\title{
Climate and clean air responses to COVID-19: a comment
}

\author{
S. M. Yasir Arafat ${ }^{1}$ (1) $\cdot$ Sarvodaya Tripathy ${ }^{2} \cdot$ Sujita Kumar Kar ${ }^{3} \cdot$ Russell Kabir $^{4}$
}

Received: 27 May 2020/Revised: 12 June 2020/ Accepted: 16 June 2020/Published online: 24 June 2020

(C) Swiss School of Public Health (SSPH+) 2020

To the Editor,

More than 5 months passed since the COVID-19 started affecting the world. The World Health Organization (WHO) had declared it a pandemic in March 2020, and most countries of the world have implemented a state of lockdown thereafter (World Health Organization 2020). The lockdown resulted in changes in lifestyle, disruption of the economy, loss of jobs, academic disruption, and many more socio-political challenges. At the same time, many positive changes also became evident. The reduction in air pollution is one of them. South-East Asian countries like India, Bangladesh, Pakistan, and Afghanistan are some of the world's most polluted countries, in terms of air quality. China which was the origin of this COVID-19 pandemic is also a country with a high level of air pollution. Delhi and its surrounding cities, for example, are considered as the topmost polluted cities in the world (IQAir nd). After lockdown in this region, there was a $49 \%$ reduction in the air quality index (AQI) as observed in a study. AQI measures pollutants like particulate matter, sulfur dioxide, nitrous oxide, etc. (The New Indian Express 2020).

Nitrogen dioxide $\left(\mathrm{NO}_{2}\right)$ is considered as a highly lethal pollutant that is emitted due to the burning of fossil fuels in vehicles. The National Aeronautics and Space

This Letter was submitted to the IJPH Call for comments:

"Climate and clean air responses to Covid-19", and reflects the author's opinion on the topic.

$\triangle$ S. M. Yasir Arafat

arafatdmc62@gmail.com

1 Department of Psychiatry, Enam Medical College and Hospital, Dhaka 1340, Bangladesh

2 Department of Microbiology, M.K.C.G. Medical College, Brahmapur, Odisha, India

3 Department of Psychiatry, King George's Medical University, Lucknow, Uttar Pradesh 226003, India

4 School of Allied Health, Faculty of Health, Education, Medicine, and Social Care, Anglia Ruskin University, Chelmsford, UK
Administration (NASA) and the European Space Agency (ESA) had released images suggesting an improvement of the environmental quality and reduction of the emission of $\mathrm{NO}_{2}$ up to $30 \%$ post-lockdown in China (Muhammad et al. 2020). Similar changes were also observed in other countries like France, Italy, Spain, and the USA. It was claimed on the basis of the satellite images of the countries before and after lockdown. Fresh images from NASA showed a rebound of $\mathrm{NO}_{2}$ level in China with the ending of lockdowns and resuming of the economic activities (NASA Earth Observatory 2020). Another study conducted in São Paulo, Brazil showed a drastic reduction in Nitric oxide, $\mathrm{NO}_{2}$, and Carbon monoxide concentrations during the lockdown phase. In the same study, they also found about a $30 \%$ increase in ozone concentrations in the urban areas that were attributable to a decrease in traffic (Nakada and Urban 2020). However, most of the studies used satellite images to measures the air pollution level in these countries, but no actual scale measurement of air pollution has been done so far globally, to check and compare the air pollution level during, before, and after the lockdown period. It is also imperative to find out how indoor air quality has changed during this lockdown as people are staying at home longer than usual.

WHO states that the bad quality of the air is associated with the death of about 7 million people which is more than road traffic accident-related deaths. Nine out of 10 individuals breathe air containing pollutants. Most of the deaths related to air pollution are due to non-communicable diseases such as $24 \%$ of brain stroke-related deaths, $25 \%$ heart disease-related deaths, $43 \%$ of lung diseases and lung cancer-related deaths are attributed to air pollution (World Health Organization 2018).

A call for comments has been made in regard to the climate and clean air responses to COVID-19 so that the proper attention could be warranted to sustain the improved air quality during the busy days of life (Agrawala et al. 2020). As lockdown was found to be an effective strategy to control all forms of pollutions, including air pollution, there is a need to think about the periodic implementation of lockdown in an organized fashion to maintain the fresh 
air quality. Now, this is the time to think about making the world more liveable by making it pollution-free. So far as the air pollution is concerned, the current COVID-19 related lockdown has been proved to be a blessing in disguise. However, country-specific, as well as culturespecific, strategies should be considered as there are strong chances of failure of universal strategies without considering the local factors. For example, measures like alternative energy sources, policies to manage economic challenges, lifestyle modifications, utilizing the natural resources can be implemented, based on the needs. All the countries should develop the air pollution surveillance system to measure, monitor, and regulate the air quality level (Kutlar Joss et al. 2017). Also, there is a need to create international pressure to raise the political will in the low- and middle-income countries. More research and funds should make ready aiming at the reduction of environmental pollution.

Funding None.

\section{Compliance with ethical standards}

Conflict of interest None.

Ethical approval Not applicable.

Informed consent Not applicable.

\section{References}

Agrawala S, Amann M, Binimelis de Raga G, Borgford-Parnell N, Brauer M, Clark H et al (2020) Call for comments: climate and clean air responses to covid-19. Int J Public Health. https://doi. org/10.1007/s00038-020-01394-3

IQAir (nd) World's most polluted cities in 2019 - PM2.5. https:// www.airvisual.com/world-most-polluted-cities. Accessed 27 May 2020

Kutlar Joss M, Eeftens M, Gintowt E et al (2017) Time to harmonize national ambient air quality standards. Int $\mathrm{J}$ Public Health 62:453-462

Muhammad S, Long X, Salman M (2020) COVID-19 pandemic and environmental pollution: a blessing in disguise? Sci Total Environ 728:138820

Nakada LYK, Urban RC (2020) COVID-19 pandemic: impacts on the air quality during the partial lockdown in São Paulo state, Brazil. Sci Total Environ 730:139087

NASA Earth Observatory (2020) Nitrogen dioxide levels rebound in china. https://earthobservatory.nasa.gov/images/146741/nitro gen-dioxide-levels-rebound-in-china?utm_source=card_2\&utm_ campaign=home. Accessed 27 May 2020

The New Indian Express (2020) Air pollution levels in Delhi drop by 49\% post-lockdown. https://www.newindianexpress.com/cities/ delhi/2020/may/12/air-pollution-levels-in-delhi-drop-by-49post-lockdown-2142473.html. Accessed 27 May 2020

World Health Organization (2018) Air pollution. World Health Organization, Geneva, Switzerland. http://www.who.int/airpollu tion/en/

World Health Organization (2020) Coronavirus. https://www.who.int/ health-topics/coronavirus\#tab=tab_1. Accessed 24 Apr 2020

Publisher's Note Springer Nature remains neutral with regard to jurisdictional claims in published maps and institutional affiliations. 